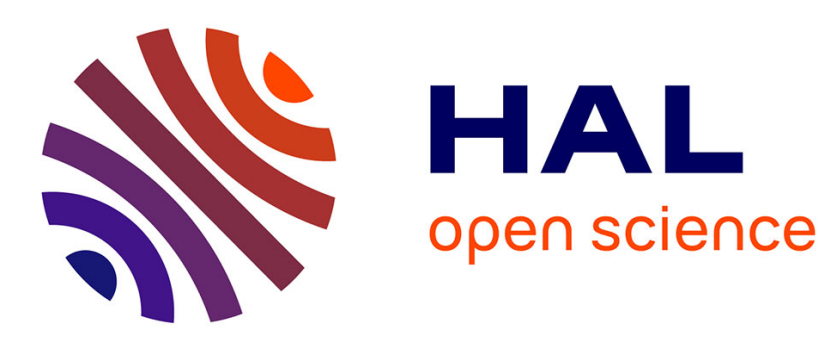

\title{
High repetition rate c.w. pumped Cr:LiSAF femtosecond regenerative amplifier
}

François Balembois, Patrick Georges, François Salin, Alain Brun

\section{To cite this version:}

François Balembois, Patrick Georges, François Salin, Alain Brun. High repetition rate c.w. pumped Cr:LiSAF femtosecond regenerative amplifier. Optics Letters, 1993, 18 (15), pp.1250. hal-00691276

\section{HAL Id: hal-00691276 \\ https://hal-iogs.archives-ouvertes.fr/hal-00691276}

Submitted on 25 Apr 2012

HAL is a multi-disciplinary open access archive for the deposit and dissemination of scientific research documents, whether they are published or not. The documents may come from teaching and research institutions in France or abroad, or from public or private research centers.
L'archive ouverte pluridisciplinaire HAL, est destinée au dépôt et à la diffusion de documents scientifiques de niveau recherche, publiés ou non, émanant des établissements d'enseignement et de recherche français ou étrangers, des laboratoires publics ou privés. 


\title{
High-repetition-rate cw-pumped $\mathrm{Cr}^{3+}: \mathrm{LiSrAlF}_{6}$ femtosecond regenerative amplifier
}

\author{
François Balembois, Patrick Georges, François Salin, ${ }^{*}$ and Alain Brun \\ Institut d'Optique Théorique et Appliquée, Unité de Recherche Associée au Centre National de la Recherche Scientifique No. 14, \\ Université Paris-Sud, B.P. 147, 91403 Orsay Cedex, France
}

Received April 21, 1993

We have developed a cw krypton-ion-laser-pumped $\mathrm{Cr}^{3+}: \mathrm{LiSrAlF}_{6}$ regenerative amplifier for femtosecond pulses operating at a $5-\mathrm{kHz}$ repetition rate. After recompression, we obtained 3.6- $\mu \mathrm{J}, 170-\mathrm{fs}$ pulses at $825 \mathrm{~nm}$. By focusing these pulses in a cell of water, we generated a white-light continuum.

Since its first demonstration by Payne et al. ${ }^{1}$ at the Lawrence Livermore National Laboratory, the $\mathrm{Cr}^{3+}: \mathrm{LiSrAlF}_{6}(\mathrm{Cr}: \mathrm{LiSAF})$ crystal has proved to be a promising laser medium. This crystal combines a large fluorescence bandwidth $(750-950 \mathrm{~nm})$ with an absorption band in the red between 600 and $700 \mathrm{~nm}$, making it particularly suitable for the development of an all-solid-state diode-pumped tunable laser. Owing to its extremely large emission band, Cr:LiSAF is well suited to the generation and amplification of ultrashort pulses. In fact, self-mode-locked femtosecond oscillators ${ }^{2,3}$ and flash-lamp regenerative amplifiers ${ }^{4}$ have already been demonstrated in Cr:LiSAF.

For high-sensitivity ultrafast experiments, highrepetition-rate femtosecond systems are desirable. One solution for such systems is to use the long energy storage time of the gain medium in $\mathrm{cw}$ pumping to amplify the pulses. Recently Norris demonstrated a cw-pumped regenerative Ti:sapphire amplifier working at a repetition rate of $250 \mathrm{kHz}$ (i.e., approximatively the inverse of the Ti:sapphire lifetime) and producing $2-\mu \mathrm{J}$ amplified pulses. ${ }^{5}$ The upper-state lifetime of Cr:LiSAF is approximately 20 times longer than that of Ti:sapphire; it is therefore possible to amplify pulses at a higher energy level while keeping the repetition rate in the multikilohertz range.

This Letter describes a Cr:LiSAF cw-pumped regenerative amplifier operating at $5 \mathrm{kHz}$ that leads to $3.6-\mu \mathrm{J}, 170-\mathrm{fs}$ pulses at $825 \mathrm{~nm}$ after recompression.

The experimental setup for the regenerative amplifier is shown in Fig. 1. We used the red lines (647 and $676 \mathrm{~nm}$ ) of a cw krypton-ion laser to pump a 15-mm-long Cr:LiSAF crystal (from Lightning Optical Corporation). Its $\mathrm{Cr}^{3+}$ concentration was 0.8 wt. $\%$, and $97 \%$ of the pump power was absorbed. In order to avoid thermal problems in the slab, we pumped the crystal on both sides. Cr:LiSAF is, in fact, of relatively poor thermomechanical quality compared with Ti:sapphire, and damage in the rod was observed at a cw pump power of $2 \mathrm{~W}$ when it was pumped from only one side. With pumping from both sides, we could reach the 3.2-W absorbed pump power level without any significant thermal effects in the crystal and without having to chop the pump laser as before. ${ }^{6}$ The cavity design consisted of a 1-m-long, folded, astigmatically compensated, fourmirror cavity. These mirrors had high reflectivity in the 800-900-nm range. The krypton-ion laser beam was focused into the Cr:LiSAF crystal by two 10-cm focal-length lenses through mirrors $\mathrm{M}_{2}$ and $\mathrm{M}_{3}$, both dichroic. A Pockels cell (Medox-EO $700 \mathrm{KD}^{*} \mathrm{P}$ ) operating at $5 \mathrm{kHz}$ and a broadband polarizer were used to trap and dump the pulses provided by a femtosecond oscillator. The polarizer was specially designed by Matra Division of Optique France to have a high transmission (100\%) for the $\pi$ polarization and a high reflection $(80 \%)$ for the $\sigma$ polarization over a wide spectral band $(\sim 50 \mathrm{~nm})$. A Faraday rotator, a half-wave plate, and a second polarizer were used together to separate the input beam and the output amplified beam. The overall transmission of these three components is greater than $95 \%$ for the output beam. The input pulses came from a femtosecond Ti:sapphire oscillator operating at a repetition rate of $82 \mathrm{MHz}$ and producing $110-\mathrm{fs}$ pulses at $825 \mathrm{~nm}$. Only $10 \mathrm{~mW}$ of average power $(0.1 \mathrm{~nJ} /$ pulse $)$ from this oscillator was injected into the regenerative amplifier.

The regenerative amplifier cavity was initially optimized without intracavity components and with a $1 \%$ output mirror. The absorbed pump power threshold was $130 \mathrm{~mW}$. The broadband polarizer was installed and optimized for minimum insertion losses (2.3\%), increasing the threshold to $320 \mathrm{~mW}$. The Pockels cell was then installed to permit $Q$-switched oper-

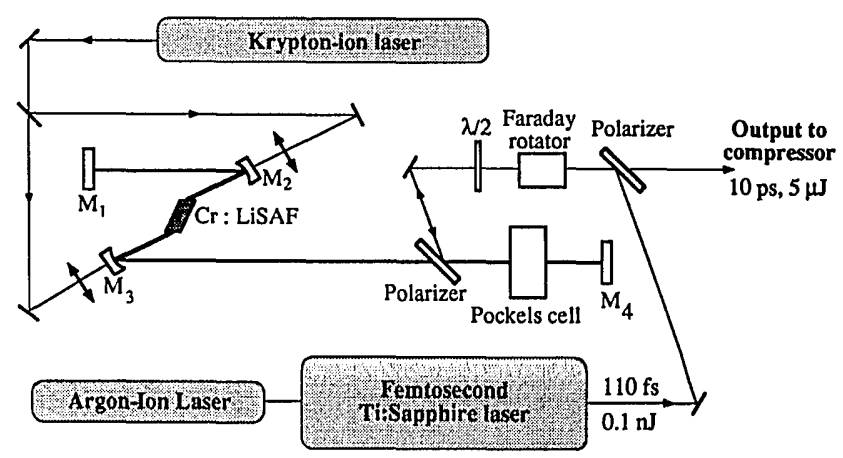

Fig. 1. Experimental setup. Mirrors $\mathrm{M}_{2}$ and $\mathrm{M}_{3}$ have $100-\mathrm{mm}$ radii of curvature. 


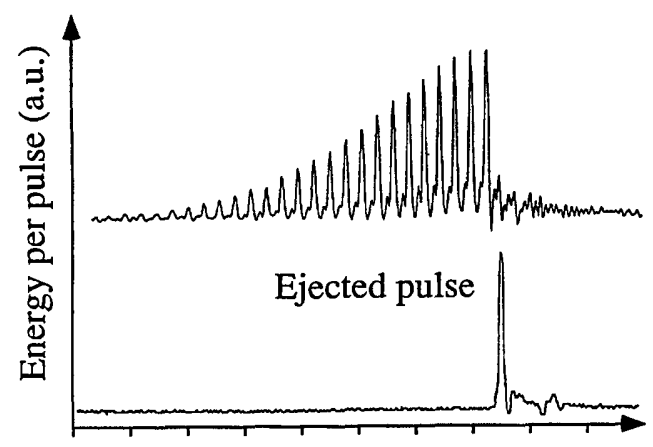

Time (20 ns / div.)

Fig. 2. Evolution of the pulse energy during the amplification. The upper curve is the intracavity pulse energy evolution.

ation. The buildup time was minimized, and, in the best configuration, the Pockels cell increased the insertion losses by $9 \%$ (480-mW threshold). Finally, we replaced the output mirror by a high-reflector mirror in the $800-900-\mathrm{nm}$ range $(450-\mathrm{mW}$ threshold). The trapping and dumping of these pulses were achieved as follows. The oscillator pulses were sent through the Faraday isolator and injected into the amplifier cavity. Initially the Pockels cell was oriented to give a quarter wave of static birefringence in order to prevent any lasing effect in the cavity. One pulse of the oscillator was then trapped in the amplifier by application of a quarter-wave voltage step on the Pockels cell. Figure 2 shows the evolution of the intracavity pulse energy. When the pulse reached saturation, it was ejected from the cavity by application of a second quarter-wave voltage step to the Pockels cell. The pulse evolution was monitored with a 1-ns rise-time photodiode (Thorlabs DET 2). By use of the electro-optic switch (Pockels cell), the pulse was ejected out of the cavity with a much better efficiency (see Fig. 2) than that obtained with acousto-optic switching. ${ }^{5}$

We first tested the efficiency of the regenerative amplifier by seeding picosecond pulses in the amplifier cavity. These pulses came from the same oscillator operating in the picosecond regime and had a duration of $\sim 100 \mathrm{ps}$. The pulse energy increased linearly with the pumping rate and reached $15.6 \mu \mathrm{J}$ at $2.4-\mathrm{W}$ absorbed pump power. We then seeded femtosecond pulses into the amplifier. The output energy increased linearly with the pump power until a pumping level of $1.5 \mathrm{~W}$ was reached and leveled off to $8 \mu \mathrm{J}$ for pump powers between 1.5 and $2.4 \mathrm{~W}$. This saturation could be explained by the increase of power density in the Cr:LiSAF slab, which would have led to important nonlinear effects. Moreover, nonlinear distortion was visible on the amplified spectrum. Between 1.5- and 2.4-W absorbed pump power, the spectrum was found to be strongly modulated (Fig. 3), certainly owing to self-phase-modulation. In order to avoid these nonlinear effects in the crystal, we reduced the energy per pulse to $5 \mu \mathrm{J}$; we worked at $1.5-\mathrm{W}$ absorbed pump power and ejected the pulses 50 ns before they reached the gain saturation (i.e., after 55 round trips). In these experimental conditions, the amplified spectrum was identical to the oscillator spectrum, indicating that there were neither nonlinear effects nor gain narrowing during amplification. The stability of the amplified pulses was found to be greater than $4 \%$ and was limited by our krypton-ion laser (Fig. 4). Because of cavity dispersion and the number of round trips in the cavity, the pulses were temporally broadened from 110 fs to $\sim 10$ ps.

We achieved the recompression of these $5-\mu \mathrm{J}$, 10 -ps pulses by using six equilateral SF10 prisms oriented at the Brewster angle, at minimum deviation, and arranged in two sets of three. ${ }^{7,8}$ The distance between the two sets of prisms was $1.8 \mathrm{~m}$. After one pass, the pulses were reflected off a flat mirror slightly tilted in the vertical direction to permit the pulses to be picked off after a second pass in the prisms. After the compressor the pulses were found to be 170 fs long, assuming a sech ${ }^{2}$ profile, with an energy of $3.6 \mu \mathrm{J}$. Note that some wings can be seen on the autocorrelation trace (Fig. 5). These may be due to third-order dispersion, misalignment of the compressor, and the optical quality of the SF10 prisms.

We focused the recompressed pulses with a $440-\mathrm{mm}$ focal-length lens in a $10-\mathrm{mm}$ water cell and observed a white-light continuum extending from 400 to $900 \mathrm{~nm}$ (limited by our detector).

The interest of this cw-pumped Cr:LiSAF regenerative amplifier lies in the possibility of red-diode pumping, inasmuch as 500-mW diodes at $670 \mathrm{~nm}$ are now commercially available (Spectra Diode Laboratories SDL 7432). As a first step to diode pumping, we tested our amplifier at $700-\mathrm{mW}$ absorbed pump power, which will potentially require only two

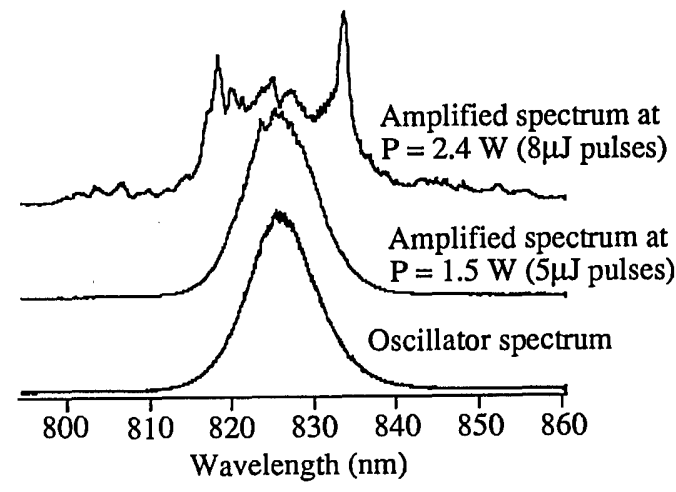

Fig. 3. Amplified spectra compared with the oscillator spectrum for two different absorbed pump powers $P$.

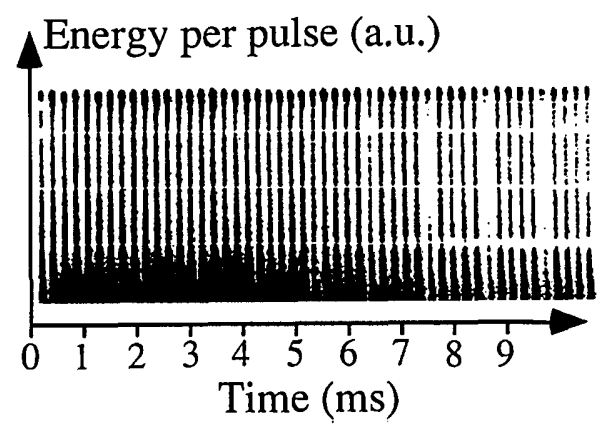

Fig. 4. Pulse stability in the millisecond scale. 


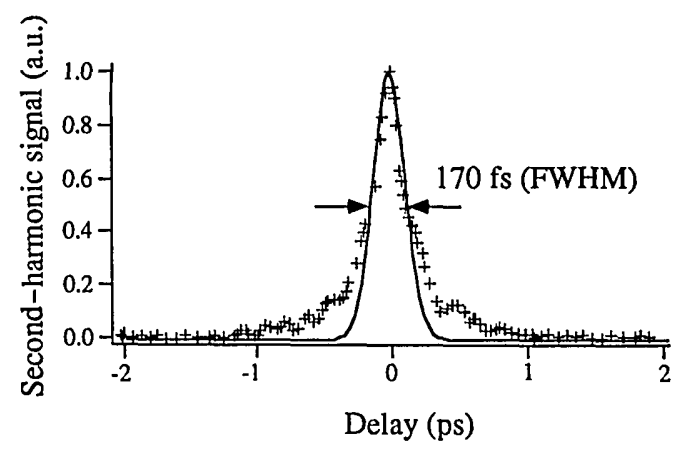

Fig. 5. Autocorrelation trace. Crosses are experimental data, and the solid curve is a theoretical fit.

SDL 7432 diodes. The regenerative amplifier then produced $3-\mu \mathrm{J}$ pulses that could be recompressed to less than $200 \mathrm{fs}$ with an energy of $2.1 \mu \mathrm{J}$ per pulse. However, the autocorrelation presented much more important wings than an autocorrelation at a pump power of $1.5 \mathrm{~W}$, because there were twice as many (130) round trips in the cavity and, hence, more important uncompensated third-order dispersion.

There are several possibilities for improvement of the efficiency of this regenerative amplifier. First, it should be possible to work at $14 \mathrm{kHz}$ (i.e., the inverse of the Cr:LiSAF lifetime) with a higher-repetitionrate Pockels cell without any decrease of energy. Second, we should be able to reach the $10-\mu \mathrm{J}$ amplification level without any nonlinear effects by increasing the spot size on the Cr:LiSAF crystal. We have calculated the $B$ integral, ${ }^{9}$ which represents the nonlinear dephasing in the slab. Assuming a cavity Gaussian beam with a waist radius of $20 \mu \mathrm{m}$ in our experiment and a nonlinear index of $0.6 \times$ $10^{-16} \mathrm{~cm}^{2} / \mathrm{W}$ for $\mathrm{Cr}:$ LiSAF, we found the $B$ integral to be $1.5 \mathrm{rad}$ for $5-\mu \mathrm{J}, 10$-ps amplified pulses and $2.4 \mathrm{rad}$ for $8-\mu \mathrm{J} 10-\mathrm{ps}$ amplified pulses. Although $2.4 \mathrm{rad}$ corresponds to a strongly modulated spectrum and is relatively close to the cited value of 3 for serious nonlinear damage and distortion, ${ }^{9}$ we observed experimentally that the mode remained $\mathrm{TEM}_{00}$, certainly owing to spatial filtering by the cavity. Our experiment shows that a $B$ integral value of 1.5 can be used to set a limit on the pulse amplification so as to avoid significant nonlinear effects. With this assumption, we can calculate that the waist in the crystal should have a radius of $50 \mu \mathrm{m}$ to reach the $10-\mu \mathrm{J}$ level without any nonlinear distortion. To do this, one would require different cavity mirrors and focusing lenses than those we currently own. Another possibility would be to use the chirped pulse amplification technique ${ }^{10}$ to avoid nonlinear effects in the crystal at the expense of an increased complexity of the system.

In conclusion, we demonstrated that this regenerative amplifier is well suited to operate at low pumping levels and to produce microjoule pulses around $825 \mathrm{~nm}$, with a duration less than $200 \mathrm{fs}$ after recompression and at a repetition rate of $5 \mathrm{kHz}$. We believe that a diode-pumped version of this Cr:LiSAF regenerative amplifier, used in combination with a diode-pumped self-mode-locked Cr:LiSAF oscillator, will lead in the future to an all-solid-state femtosecond system producing microjoule pulses at a $\sim 10-\mathrm{kHz}$ repetition rate.

The authors thank Spectra-Physics France for the loan of a Tsunami system and Coherent Scientifique for the loan of a Mira 900 system.

${ }^{*}$ Present address, B.M. Industries, 7 rue du Bois Chaland, CE 2901 Lisses 91029, Evry Cedex, France.

\section{References}

1. S. Payne, L. Chase, L. Smith, W. Kway, and H. Newkirk, Appl. Phys. 66, 1051 (1989).

2. A. Miller, P. LiKamWa, B. H. T. Chai, and E. W. Van Stryland, Opt. Lett. 17, 195 (1992).

3. N. H. Rizvi, P. M. W. French, and J. R. Taylor, Opt. Lett. 17, 1605 (1992).

4. M. Perry, D. Strickland, T. Ditmire, and F. Patterson, Opt. Lett. 17, 604 (1992).

5. T. B. Norris, Opt. Lett. 17, 1009 (1992).

6. F. Balembois, P. Georges, F. Salin, G. Roger, and A. Brun, in Digest of Conference on Advanced Solid-State Lasers (Optical Society of America, Washington, D.C., 1993), p. 276.

7. J. D. Kafka, M. L. Watts, D. J. Roach, M. S. Keustead, $\mathrm{H}$. W. Schaaf, and T. Baer, in Conference on Lasers and Electro-Optics, Vol. 7 of 1990 OSA Technical Digest Series (Optical Society of America, Washington, D.C., 1990), paper PD8.

8. M. Hofer, M. E. Ferman, F. Haberl, M. H. Ober, and A. J. Schmidt, Opt. Lett. 16, 502 (1991).

9. A. E. Siegman, Lasers (University Science, Mill Valley, Calif., 1986), p. 385.

10. D. Strickland and G. Mourou, Opt. Commun. 56, 219 (1985). 